\title{
Diastolic properties of the normal left ventricle during supine exercise
}

\author{
HIROSHI NONOGI, OTTO M HESS, MANFRED RITTER, \\ HANS P KRAYENBUEHL \\ From the Medical Policlinic, Cardiology, University Hospital, Zurich, Switzerland
}

SUMMARY Diastolic function in response to dynamic exercise was studied by biplane left ventriculography and by measuring left ventricular pressure with a high fidelity micromanometer? tipped catheter at rest and during supine bicycle exercise in nine normal subjects. During exercise ${ }^{\circ}$ there was a fall in end systolic volume, in the time constant of left ventricular isovolumic pressure $\vec{\omega}$ decay, and in the lowest diastolic pressure. Stroke volume, peak filling rate, mean passive fillingo rate, and the volume at the lowest diastolic pressure increased. There was an increase in the number of time constants that had elapsed before the lowest diastolic pressure was reached and the slope of the pressure-volume curves during passive filling $(\Delta \mathrm{P} / \Delta \mathrm{V})$ increased without changes in ence diastolic pressure and volume.

These results show that during exercise elastic recoil is enhanced and left ventricular relaxation is faster and more complete. Both phenomena reduce the lowest diastolic filling pressure. Thi observed increase in chamber stiffness from rest to exercise is probably related to increasedf resistance of the left ventricular wall caused by higher passive filling rates. The enhanced early diastolic pressure decay during exercise allows stroke volume to increase despite an increase in diastolic viscoelastic resistance and chamber stiffness.

The effects of dynamic exercise on left ventricular function have been analysed in many studies and by various techniques. Attention has focused mainly on the contractile or systolic performance of the left ventricle in experimental ${ }^{1-3}$ and clinical studies. ${ }^{4-6}$ Little is known about the diastolic function of the normal heart during exercise. There is general agreement that left ventricular end systolic volume is smaller during exercise than at rest and most investigators have reported an increase in stroke volume during exercise. These data are consistent with a enhanced contractility during exercise, but the role of the Frank-Starling mechanism in the normal heart remains uncertain. ${ }^{578}$ In most studies, left ventricular end diastolic volume and stroke volume are maintained during exercise despite shortening of the

Requests for reprints to Dr Otto M Hess, Medical Policlinic, Division of Cardiology, University Hospital, Raemistrasse 100, 8091 Zurich, Switzerland.

Accepted for publication 23 November 1987 diastolic filling interval, whereas in pacing-induced. tachycardia, both end diastolic volume and stroke volume are reduced..$^{90}$ Recently, Higginbotham et a showed that at low levels of upright exercise end diastolic volume and stroke volume increase, whereas at maximum levels of exercise end diastolic volume decreases with no further increase in stroke volume. ${ }^{10}$ These findings suggest that filling is enhanced but it is not known whether and to what extent the passiver properties of the left ventricular chamber in diastoles are altered during exercise.

In the present study the response of diastolic function to dynamic exercise in normal hearts was evaluated by simultaneously measuring left ven 0 tricular pressures and left ventricular volumes dur $\omega$ ing submaximal supine exercise.

\section{Patients and methods}

PATIENTS

We studied nine patients (eight men, one woman aged 35-58, (mean 49)) referred to our hospital for evaluation of chest pain. Five had no cardiovasculan abnormalities. Three had minimal coronary artery 
disease (maximal coronary stenosis $<50 \%$ of the luminal diameter) and one had mitral valve prolapse without mitral regurgitation. They had normal systolic function as defined by resting left ventricular ejection fraction $\geqslant 57 \%$ (the lower limit of normality of our laboratory). ${ }^{12}$ The day before catheterisation, all patients had an upright bicycle exercise test and showed normal exercise tolerance (mean work load $132 \mathrm{~W}$ ) with no ST segment changes and no anginal pain. All patients gave informed consent, and no complications occurred in any of them.

\section{CATHETERISATION AND CINEANGIOGRAPHY}

An hour before catheterisation patients were premedicated with $10 \mathrm{mg}$ of oral chlordiazepoxide. Cardiovascular medications were not given for 12 to 24 hours before the study. Left ventricular pressure was measured with a 8 F Millar pigtail angiographic micromanometer catheter introduced from the right femoral artery. The pressures were recorded at a paper speed of $250 \mathrm{~mm} / \mathrm{s}$ (Electronics for Medicine, VR-12) together with the first derivative of pressure $(\mathrm{dP} / \mathrm{dt})$ and $(\mathrm{dP} / \mathrm{dt}) / \mathrm{P}$ (fig 1$)$. Before recording at rest and during exercise the micromanometer was calibrated by superimposing the high fidelity pressure tracing on the pressure tracing obtained with a fluid filled catheter. Biplane left ventriculography was performed in the $30^{\circ}$ right and $60^{\circ}$ left anterior oblique projections at a filming rate of 50 frames per second (Siemens Angioscope). Each angiographic frame had a digital time that corresponded to the time marks on the pressure recordings. A metal sphere of known diameter was filmed in the position of the heart for calibration purposes at the end of the procedure. The patients held their breath in midinspiration during the resting angiogram. If respiration related pressure changes were noted during exercise we selected angiographic beats recorded during mid-inspiration. During cineangiography Valsalva manoeuvres were avoided by instructing the patient, observing the diaphragm, and monitoring right atrial pressure.

\section{EXERCISE PROTOCOL}

All patients had upright bicycle exercise testing before catheterisation to determine the exercise tolerance. At catheterisation, pressures were recorded before and after the patient's feet were attached to the pedals of the bicycle. All data at rest were recorded during acquisition of the first angiogram while the patient's feet were raised. After the resting angiogram had been obtained and after a 12-15 minute pause to allow left ventricular pressure to return to the control value, the patient started to exercise at a low level. The work load was increased every two minutes until limiting symptoms occurred or the predicted submaximal heart rate was achieved. At peak exercise pressures were again recorded with simultaneous cineangiography. Coronary arteriography was performed by the Judkins technique at the end of the exercise test.

\section{DATA ANALYSIS}

We analysed only sinus beats and excluded postextrasystolic beats. Pressure tracings were digitised for an entire cardiac cycle with an electronic digitiser (Numonics Corporation) interfaced with a computer (PDP 11/34). Pressure and dP/dt values were plotted
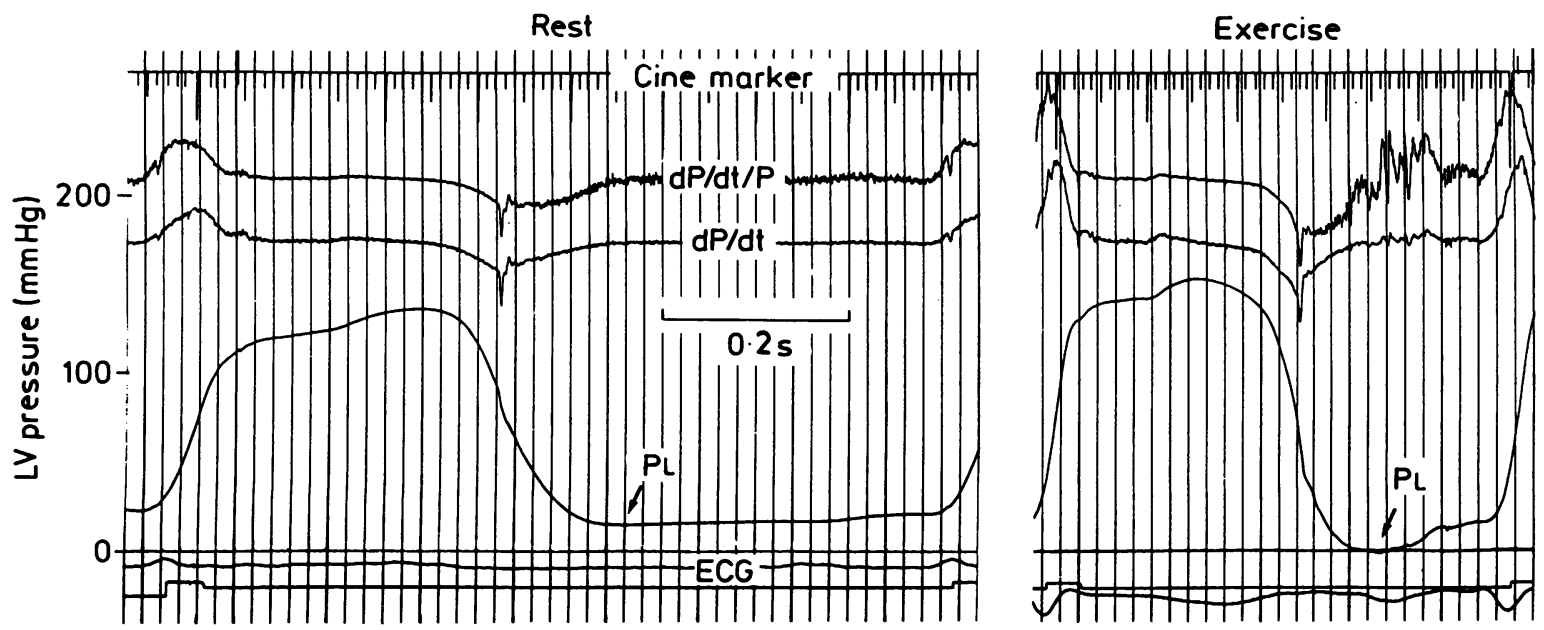

Fig 1 The left ventricular ( $L V$ ) pressure tracing in the resting state (left) and during exercise (right). The exercise beat had a higher peak systolic pressure but the end diastolic pressure (EDP) was unchanged. The lowest diastolic pressure $\left(P_{L}\right)$ was lower during exercise. 


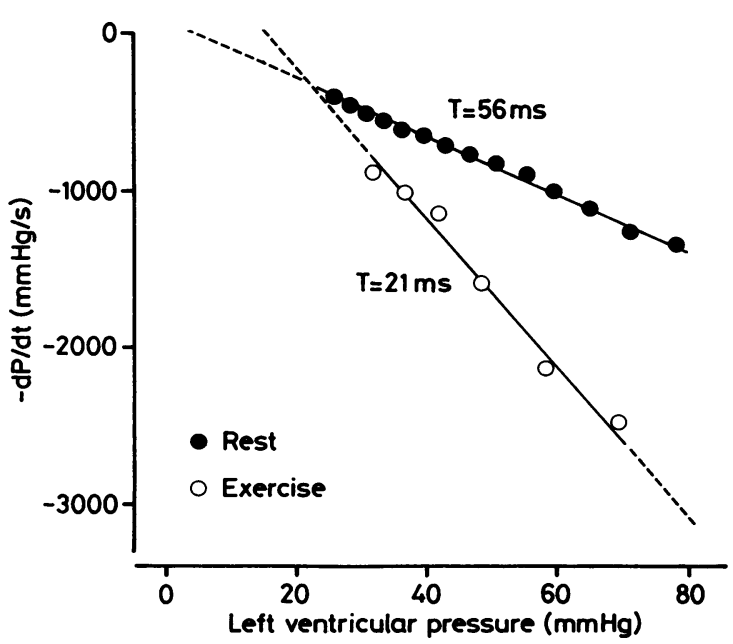

Fig 2 Left ventricular pressure and negative $d P / d t$ coordinates measured during the isovolumic relaxation period. The time constant of relaxation $(T)$ is represented by the negative reciprocal of the slope of the linear regression between pressure and $d P / d t$ coordinates. During exercise $T$ decreased to $21 \mathrm{~ms}$ from a control value of $56 \mathrm{~ms}$. This result shows that the speed of relaxation was increased during dynamic exercise.

every 2.5 to $5 \mathrm{~ms}$ depending on the heart rate. The time constant for left ventricular pressure decay was calculated as the negative reciprocal of the slope relating left ventricular pressure to $\mathrm{dP} / \mathrm{dt}$ coordinates between peak negative $\mathrm{dP} / \mathrm{dt}$ and the time at which pressure had decreased to $5 \mathrm{~mm} \mathrm{Hg}$ above left ventricular end diastolic pressure (fig 2 ). To study the completeness of relaxation, we used the technique of Weisfeldt $e t$ al, which assumes relaxation to be $97 \%$ complete at 3.5 time constants after peak negative $\mathrm{dP} / \mathrm{dt} .{ }^{13} \mathrm{We}$ calculated the number of time constants that had elapsed before the time of the lowest diastolic pressure. Left ventricular angiograms for one cardiac cycle were analysed frame by frame by the area-length method. ${ }^{14}$ End diastole was defined as the beginning of the rapid rise of left ventricular pressure immediately after the start of the QRS complex. End systole was defined as the angiographically determined point of aortic valve closure.

Left atrial pressure is a major determinant of left ventricular filling. ${ }^{15}$ Because left atrial pressure was not measured in the present study, we recorded the pressure at the time at which unopacified blood first entered the ventricle. ${ }^{16-18}$ In a previous report we compared the transseptally measured peak left atrial $\mathrm{v}$ wave pressure (mitral valve opening pressure) and the left ventricular pressure at the time when unopacified blood first entered the ventricle in $\frac{I}{\Phi}$ patients with aortic stenosis. ${ }^{18}$ The correlation between both pressures was good $(r=0.911 ; p<c$ 0.001 ). The peak $v$ wave pressure was slightly higher $(14 \%)$ than the pressure when unopacified blood first entered the ventricle. In the present study the pressure when unopacified blood first entered the ventricle correlated significantly $(r=0.68, n=18 ; p$ $<0.01$ ) with end diastolic pressure. Thus the pressure when unopacified blood first entered the ventricle is not the true driving pressure but was used as an index of the left atrial pressure responsible for mitral valve opening.

End diastolic volume, end systolic volume, stroke volume, and ejection fraction were calculated according to standard formulas. Volumes were standardised for body surface area. Early filling volume (volume at the time of the lowest diastolic pressure minus volume at mitral valve opening) was expressed as the percentage of total diastolic filling volume (early filling fraction). ${ }^{19}$ Instantaneous diastolic filling rates were calculated every $20 \mathrm{~ms}$ after mitral valve opening. To minimise errors caused by random noise in the left ventricular volume-time curve, raw data were filtered with the fifth-grade moving average. ${ }^{18}{ }^{20}$ Then diastolic filling rate was calculated by a third-degree polynominal function. The highest value occurring early in diastole was termed the peak filling rate. The mean passive filling rate was defined as the volume change from the lowest diastolic pressure to end diastole divided by its time interval. A simple assessment of left ventricular chamber stiffness was calculated as the index $\Delta \mathrm{P}$ (end diastolic pressure minus the lowest diastolic pressure) divided by $\Delta \mathrm{V}$ (end diastolic volume minus the volume at the lowest diastolic pressure). ${ }^{21}$

\section{STATISTICAL ANALYSIS}

Results are presented as group means (1 SD) in the tables and mean ( $1 \mathrm{SE}$ ) in fig 4 . Means at rest and exercise were compared by a paired $t$ test. The level of statistical significance was defined as $\mathrm{p}<0.05$.

\section{Results}

Table 1 shows the left ventricular angiographic data and table 2 the pressure data. Leg elevation before exercise was associated with an increase in the left 0 ventricular end diastolic pressure from 10 (3) to $\bar{D}$ 19 (5) $\mathrm{mm} \mathrm{Hg}(\mathrm{p}<0.001)$, in the lowest diastolic ? pressure from 4 (3) to 9 (4) $\mathrm{mm} \mathrm{Hg}(\mathrm{p}<0.001)$, and in right atrial pressure (six patients) from 3 (1) to 8 (3) $\mathrm{mm} \mathrm{Hg}(\mathrm{p}<0.001)$. The heart rate remained unchanged (from 67 (16) to 69 (17) beats/min). The increase in preload accounts for this increase in filling 
Iable 1 Angiographic data at rest and during supine exercise in nine patients with normal left ventricular function

\begin{tabular}{|c|c|c|c|c|c|c|c|c|c|c|}
\hline Patients & $H R$ & Work & $E D I^{\circ}$ & $E S V$ & $S V$ & $E F$ & $P F R$ & $M F R$ & ${ }^{\prime \prime} V^{\prime}{ }^{\prime}$ & $V_{P_{t}}$ \\
\hline 1 Rest & 56 & - & 98 & 38 & 6) & 61 & 217 & 93 & 13 & 46 \\
\hline Ex & 88 & 50 & 111 & 32 & 79 & 71 & 395 & 225 & 43 & 66 \\
\hline 2 Rest & 71 & - & 41 & 27 & 64 & 70 & 315 & 140 & 28 & 38 \\
\hline $\mathrm{Ex}$ & 111 & 50 & 98 & 27 & 71 & 72 & 578 & 231 & 33 & 61 \\
\hline 3 Rest & 71 & - & 90 & 31 & 59 & 66 & 361 & 129 & 9 & 41 \\
\hline Ex & 107 & 100 & 96 & 31 & 65 & 68 & 398 & 257 & 41 & 63 \\
\hline+ Rest & 71 & - & 49 & +3 & 56 & 57 & 257 & 136 & 13 & 50 \\
\hline $\mathrm{Ex}$ & 125 & 120 & 104 & 36 & 68 & 65 & 493 & 325 & 29 & 65 \\
\hline 5 Rest & 88 & - & 78 & 26 & 52 & 67 & 264 & 175 & 19 & 36 \\
\hline $\mathrm{Ex}$ & 150 & 100 & 84 & 26 & 58 & 69 & 014 & 363 & 73 & 55 \\
\hline (6) Rest & 57 & $\ldots$ & 104 & +3 & (1) & 59 & 258 & 88 & 40) & 6) \\
\hline $\mathrm{Vx}$ & 103 & 100 & 113 & +3 & 70 & 62 & 372 & 281 & 36 & 68 \\
\hline 7 Rest & 51 & - & 87 & 20 & ol & 70 & $26 x$ & 64 & 24 & th \\
\hline Ex & 115 & 100 & 80 & 22 & 58 & 73 & 346 & 200 & 45 & 49 \\
\hline 8 Rest & 101 & $\ldots$ & 80 & 30 & 56 & 65 & +33 & 281 & 15 & 47 \\
\hline Ex & 136 & o) & 79 & 21 & 58 & 73 & 629 & +20 & 22 & 37 \\
\hline 9) Rest & 55 & - & 0.1 & 34 & h) & ot & 316 & 65 & 26 & 59 \\
\hline Ex & 130 & 140 & 99 & 24 & 75 & 76 & 788 & 530 & 33 & 48 \\
\hline \multirow{2}{*}{$\begin{array}{l}\text { Rest Mean } \\
\text { SI) }\end{array}$} & 69) & $\ldots$ & 92 & 33 & 59 & 64 & 209 & 130 & 21 & 47 \\
\hline & 17 & & 8 & 7 & $t$ & 5 & 66 & 68 & 10 & 8 \\
\hline \multirow{2}{*}{$\begin{array}{ll}\text { Ex } & \text { Mce } \\
\text { SI) }\end{array}$} & 118 & 91 & 96 & 29 & 67 & 70 & 512 & 315 & 4) & 57 \\
\hline & 19 & 31 & 13 & 7 & 8 & 4 & 150 & 108 & 15 & 10 \\
\hline$p$ & $\cdot(0.0101$ & & is & $<0.05$ & $=(1 .(1) 1$ & .0101 & ( 0.01 & .0 .01 & $=0.05$ & $\cdot 0.05$ \\
\hline
\end{tabular}

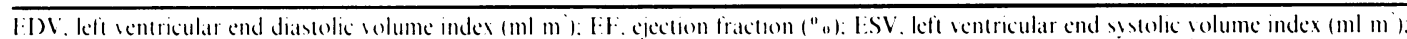

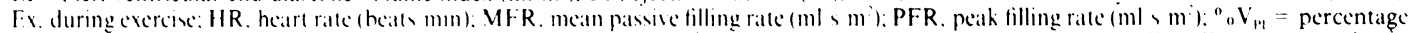

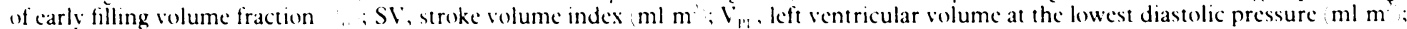
work, crgometric work load $\mathbb{W}$

pressures. All resting data were measured during the first angiogram and with the patients' legs raised.

\section{ANGIOGRAPHIC DATA}

Patieuts achieved at peak exercise a mean workload of $91 \mathrm{~W}$ after 3.7 minutes of exercise. No patient had exercise induced angina. Heart rate increased from
69 to 118 beats min. Left ventricular end diastolic volume was similar at rest and during exercise, whereas end systolic volume decreased from 33 to 29 $\mathrm{ml} \mathrm{m}^{2}(\mathrm{p}<0.05)$. Left ventricular stroke volume and ejection fraction increased significantly during exercise (from 59 to $67 \mathrm{ml} \mathrm{m}^{2}$ (p<0)(01) and from 64 to $70^{\prime \prime},(\mathrm{p}<0.01)$ respectively $)$. During exercise the

Table 2 Pressure data at rest and during supine exercise in nine patients with normal left centricular function

\begin{tabular}{|c|c|c|c|c|c|c|c|c|c|c|c|c|}
\hline & & I.LP & EDP & $P_{i}$ & $d P d t$ & $-d P d t$ & $R \cdot A P$ &.$M I^{\circ}() P$ & $T$ & $P_{R}$ & $T: a t P$ & $11^{\prime} 11^{\circ}$ \\
\hline \multirow[t]{2}{*}{$\overline{1}$} & Rest & 95 & 17 & 9 & 963 & 909 & - & y & 516 & 1.4 & 24 & 0.15 \\
\hline & $\mathrm{Ex}$ & 123 & 16 & 0 & 2031 & 1567 & - & 8 & 35.0 & (1). 1 & 3.7 & 0.23 \\
\hline \multirow{2}{*}{2} & Rest & 151 & 21 & 13 & 1941 & 2076 & 12 & 15 & 47.0 & 0.2 & $2 \cdot 3$ & 0.10 \\
\hline & Ex & 141 & 17 & 2 & 2434 & 2620 & 12 & 10 & $28 \cdot 3$ & 51 & 34 & (1) 42 \\
\hline \multirow{2}{*}{3} & Rest & 136 & 18 & 9 & 1466 & 1808 & 10 & 9 & 38.6 & -0.5 & $2 \cdot h$ & (1). 18 \\
\hline & $\mathrm{Ex}$ & 193 & 18 & 7 & 2703 & 2802 & 10 & 10 & 19.2 & 8.6 & 3.6 & (1).29 \\
\hline \multirow{2}{*}{4} & Rest & 126 & 22 & 14 & 1490 & 1399 & - & 14 & 55.9 & $2 \cdot 1$ & $2 \cdot 3$ & 0.10 \\
\hline & Fx & 153 & 13 & 2 & 3204 & 2500 & - & 12 & $23 \cdot 0$ & 13.4 & 3.8 & 0.28 \\
\hline \multirow{2}{*}{5} & Rest & 123 & 14 & 5 & 2227 & 1523 & 3 & 11 & 38.5 & -5.5 & $2 \cdot 7$ & 0.23 \\
\hline & Ex & 154 & 18 & 3 & 4477 & 2811 & 9 & 22 & 18.0 & $2 \cdot 0$ & 3.3 & (1.52 \\
\hline \multirow[t]{2}{*}{6} & Rest & 163 & 20 & 10 & 1369 & 1856 & 11 & 14 & 52.8 & 4.8 & $3 \cdot 1$ & (1) 22 \\
\hline & $\mathrm{Ex}$ & 173 & 26 & 5 & 2562 & 2360 & 12 & 22 & 20.7 & $10 \cdot 8$ & 43 & 0.47 \\
\hline \multirow[t]{2}{*}{7} & Rest & 114 & 12 & 4 & 1474 & 1375 & 7 & 10 & 53.6 & -8.8 & $2 \cdot 3$ & 1) 18 \\
\hline & Fx & 131 & 17 & 3 & 3357 & 2225 & 9 & 13 & 19.0 & 13.4 & +2 & (1).4.4 \\
\hline \multirow[t]{2}{*}{8} & Rest & 134 & 23 & 5 & 1992 & 2296 & 6 & 14 & 26.5 & $2 \cdot 4$ & 3.3 & (1).40 \\
\hline & Ex & 151 & 20) & 2 & 3057 & 2703 & $n$ & i & 12.7 & 0.5 & 4.5 & 0.42 \\
\hline \multirow[t]{2}{*}{9} & Rest & 103 & 27 & 16 & 1282 & 1541 & - & 17 & 58.1 & 0.5 & 23 & (1) 32 \\
\hline & Ex & 171 & 30 & 1 & +104 & 377.4 & - & 2.1 & 1.4 .5 & 22.7 & $5 \cdot 2$ & 0.5. \\
\hline \multirow{2}{*}{\multicolumn{2}{|c|}{$\begin{array}{l}\text { Rest Mean } \\
\text { SD }\end{array}$}} & 134 & 19 & 9 & 1578 & 1643 & 8 & 13 & 470 & -3.1 & 20 & (1).22 \\
\hline & & 23 & 5 & 4 & 398 & +16 & 3 & 3 & 10.4 & 3.4 & 0.4 & 0.08 \\
\hline \multirow{2}{*}{\multicolumn{2}{|c|}{$\begin{array}{ll}\text { Ex } & \begin{array}{l}\text { Mean } \\
\text { SD }\end{array}\end{array}$}} & 154 & 19 & 3 & 3103 & 2604 & 10 & 15 & 212 & 7.9 & 40 & (1).40 \\
\hline & & 22 & 5 & 2 & 792 & 588 & 2 & 0 & 0.9 & 2.9 & 0.0 & (1).11 \\
\hline \multicolumn{2}{|c|}{$\mathrm{p}$} & $<0 \cdot(0) 5$ & $\mathrm{NS}$ & $<0.01$ & $<(0.001$ & $=0.0(0) 1$ & $\mathrm{NS}$ & is & $\cdot 0.0(0) 1$ & -0.01 & $\cdot(0.0(1) 1$ & (1) (0)1 \\
\hline
\end{tabular}

$\mathrm{dP} \mathrm{dt}$, peak positive $\mathrm{dP} \mathrm{dt}(\mathrm{mm} \mathrm{Hg} \mathrm{s}$; EDP, left ventricular end diastolic pressure $\mathrm{mm} \mathrm{Hg}$ ) L.VP. left ventricular peak systolic pressure $\mathrm{mm} \mathrm{Hg}$ :

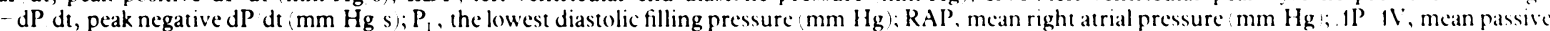

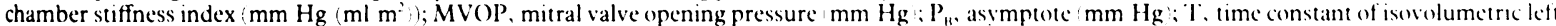
ventricular pressure decay $(\mathrm{ms}) ;$; ' $\mathrm{s}$ at $P_{1}$, the number of T's clapsed at $P_{1}$. 


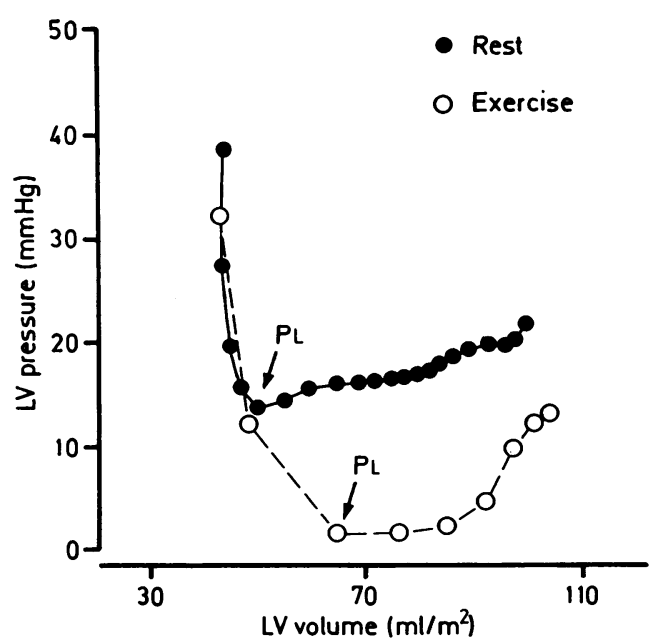

Fig 3 Representative pressure $(P)$-volume $(V)$ plots in a patient with normal left ventricular function. In the exercise beat the diastolic curve is shifted downward and the slope is steeper than in the resting beat without any change in end diastolic volume. This result suggests a decrease in chamber compliance during exercise.

peak filling rate and mean passive filling rate increased markedly ( 299 to $512 \mathrm{ml} / \mathrm{s} / \mathrm{m}^{2}(\mathrm{p}<0.01)$ and 130 to $315 \mathrm{ml} / \mathrm{s} / \mathrm{m}^{2}(\mathrm{p}<0.01)$ respectively) without a change in mitral valve opening pressure. Early filling fraction and left ventricular volume at the lowest diastolic pressure increased significantly during exercise (21 to $40 \%(p<0.05)$ and 47 to 57 $\mathrm{ml} / \mathrm{m}^{2}(\mathrm{p}<0.05)$ respectively).

\section{PRESSURE DATA}

Left ventricular peak systolic pressure increased significantly during exercise as did peak positive $\mathrm{dP} /$ dt. The lowest diastolic pressure was lower during exercise ( 9 to $3 \mathrm{~mm} \mathrm{Hg}, \mathrm{p}<0.01$ ) than at rest whereas left ventricular end diastolic pressure remained unchanged. Right atrial pressure also remained unchanged. The time constant decreased during exercise $(47$ to $21 \mathrm{~ms}(\mathrm{p}<0.001))$ with an increase in peak negative $\mathrm{dP} / \mathrm{dt}$ and in the number of time constants that had elapsed before the lowest diastolic pressure was reached (from 2.6 to $4.0, p<$ 0.001 ). These findings suggest a more complete relaxation during exercise than at rest.

\section{PRESSURE-VOLUME RELATION}

The index $\Delta \mathrm{P}(\mathrm{mm} \mathrm{Hg}) / \Delta \mathrm{V}\left(\mathrm{ml} / \mathrm{m}^{2}\right)$ increased significantly during exercise because the driving pressure increased more for a similar increase in diastolic volume during exercise than it did at rest. Figure 3 shows a representative example of a left ventricular pressure-volume plot. Figure 4 shows the pooled diastolic pressure-volume data of all nine patients. During exercise a decrease in the lowest diastolic pressure was accompanied by an increase in volume.

Both left ventricular end diastolic pressure and volume remained unchanged during exercise. The diastolic pressure-volume curve, however, showed a downward shift and an increase in slope during exercise. These findings suggest an increase in chamber stiffness during exercise. In order to assess the mechanism of increased chamber stiffness during exercise, we analysed the relation between pressure increase $(\Delta \mathrm{P})$ and mean passive filling rate (fig 5 ). There was a significant correlation (coefficient 0.84 $(p<0.001))$. An increase in passive filling rate is accompanied by an increase in $\Delta \mathbf{P}$.

To assess the effect of left ventricular volume at the lowest diastolic pressure on chamber stiffness, we compared left ventricular volume and early filling fraction at the lowest filling pressure with the index $\Delta \mathrm{P}$ divided by $\Delta \mathrm{V}$. There was no significant correlation between left ventricular volume at the lowest diastolic pressure and $\Delta \mathrm{P} / \Delta \mathrm{V}$, whereas there was a weak but significant correlation $(\mathrm{r}=0.54, \mathrm{p}<0.05)$ between early filling fraction and $\Delta \mathrm{P} / \Delta \mathrm{V}$.

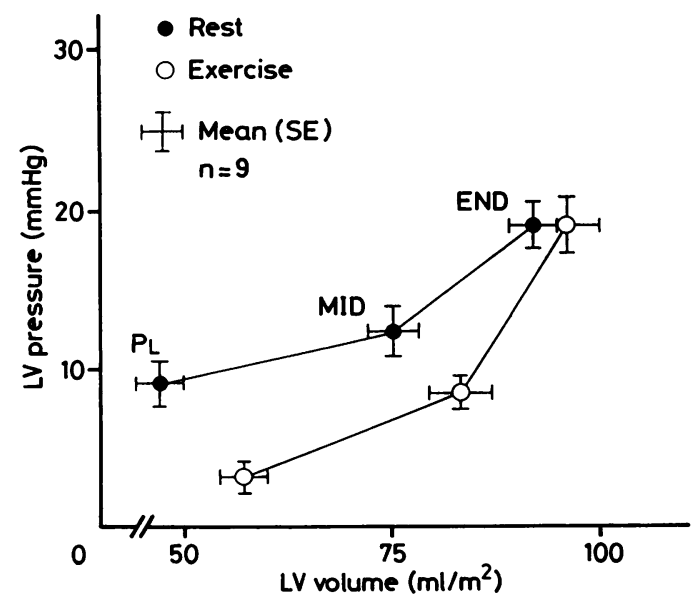

Fig 4 Mean (1 SE) diastolic pressure (P)-volume (V) relations for all nine patients at rest and during exercise. Coordinates of left ventricular ( $L V$ ) pressure and volume are averages at three reference points: the lowest diastolic pressure $\left(P_{L}\right)$, mid-diastole (MID), and end diastole (END). $P_{L}$ was lower during exercise than at rest and there was a slight increase in volume. Both end diastolic pressure and volume remained unchanged during exercise. The pressure-volume curve showed a downward shift and an increase in slope during exercise. 


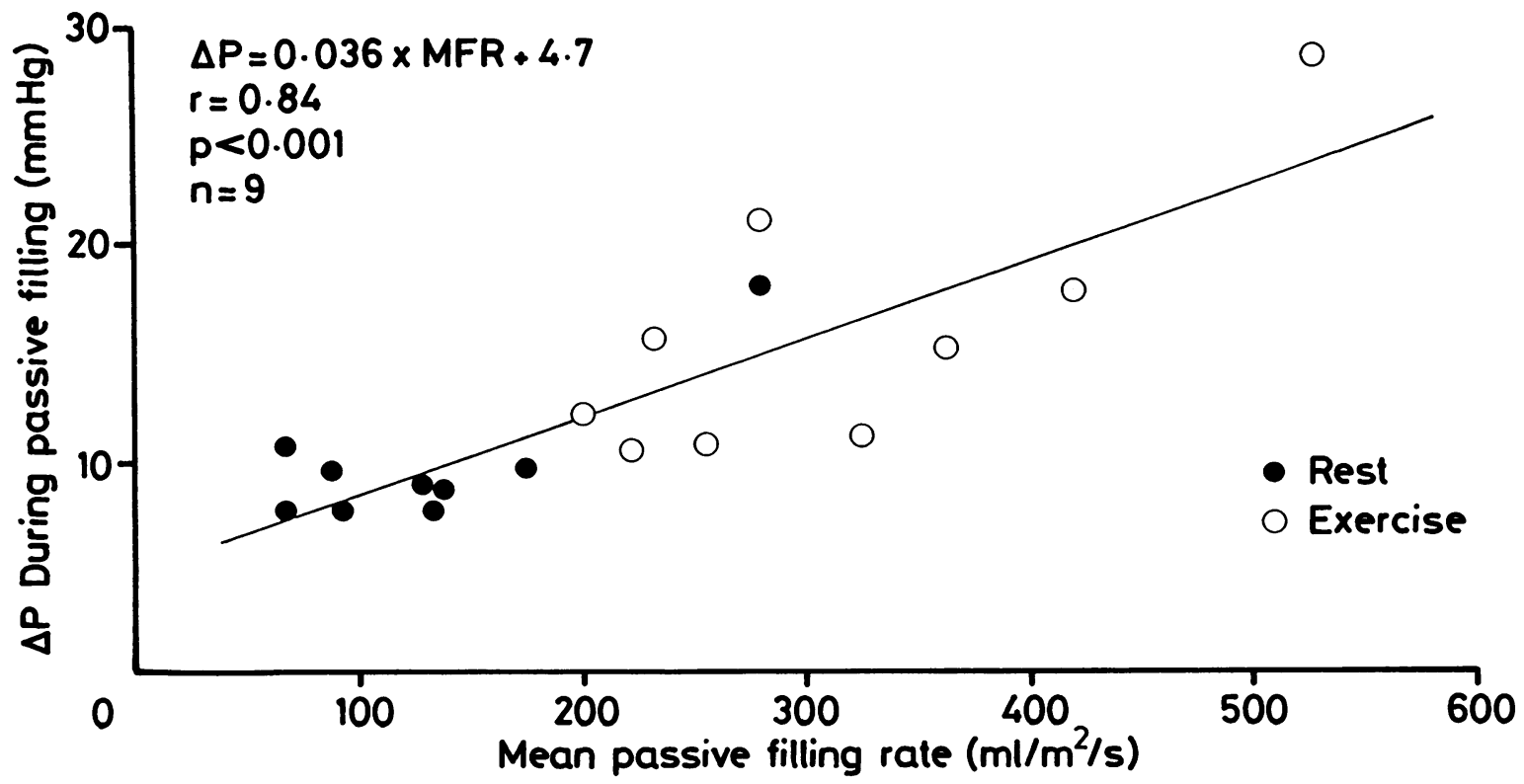

Fig 5 The correlation between the pressure increase $(\triangle P)$ and mean passive filling rate $(M F R)$ was good ( $r=0 \cdot 84)$. An increase in filling rate was accompanied by an increase in $\triangle P$.

\section{Discussion}

\section{FILLING DYNAMICS AND RELAXATION DURING EXERCISE}

In the present study the peak filling rate and early diastolic filling fraction were enhanced during exercise. Two mechanisms must be considered in the interpretation of changes in filling dynamics during exercise in normal subjects.

The first mechanism is the elastic recoil (or diastolic suction) created by systolic contraction. The magnitude of elastic recoil is inversely related to end systolic volume ${ }^{22}$ or depends on the extent of muscle shortening during systole. ${ }^{23}$ In animal studies obstruction of the left ventricular inflow produced negative intraventricular pressures, and at small ventricular volumes the pressure-volume curve fell below the zero pressure line. ${ }^{24} 25$ Ventricular suction augments filling and maintains relatively low filling pressure when heart rate is high during exercise..$^{22}$ In the present study, end systolic volume decreased slightly ( $p<0.05)$ during exercise (a slight decrease in five patients and no change in four patients), while stroke volume increased in eight patients. This condition may be associated with a mild enhancement in elastic recoil.

The second mechanism is related to the enhancement of left ventricular relaxation during exercise. Influences of relaxation on early diastolic filling have been studied in animal models and human subjects. ${ }^{26-28}$ During exercise relaxation is enhanced both by an increase in sympathetic tone and an increase in heart rate. ${ }^{29}{ }^{30}$ In the present study during exercise there was a faster, more complete left ventricular relaxation with a decrease in the time constant and an increase in the number of time constants that elapsed before the lowest diastolic pressure was reached.

The left atrial driving pressure after mitral valve opening is another important determinant of filling, especially in the diseased heart. ${ }^{1517} 18$ In the present study, left atrial pressure was not recorded but the index of mitral valve opening pressure remained unchanged at rest and during exercise. Thus the atrial driving pressure is not a major determinant of left ventricular filling during exercise in the normal left ventricle. Atrioventricular flow depends on the atrioventricular pressure gradient. ${ }^{15}$ In the present study, the mitral valve opening pressure was unchanged while the lowest left ventricular filling pressure decreased during exercise, suggesting an increase in the atrioventricular pressure gradient. The maintenance of low diastolic pressures with augmented filling and enhanced relaxation is beneficial during exercise when diastole is considerably shortened.

PASSIVE DIASTOLIC PROPERTIES DURING EXERCISE

During exercise, the diastolic pressure-volume 
curves showed a downward shift and an increase in slope (figs 3 and 4). These findings suggest an increase in chamber stiffness during passive diastolic filling. The change in left ventricular chamber stiffness may be attributed to several extrinsic or intrinsic mechanisms. Alterations in right ventricular loading conditions and pericardial constraint seem to be unlikely because the right atrial pressure remained unchanged during exercise. Tomoike $e t$ al showed that left ventricular end diastolic pressure rose significantly above the control values during strenuous exercise in normal dogs with an open pericardium but end diastolic segment length increased only slightly. ${ }^{3}$ Also during exercise with regional ischaemia there was no significant elongation of the control segment length even though the left ventricular end diastolic pressure was higher during ischaemia. ${ }^{3}$

Another mechanism of abnormal diastolic function is related to changes in coronary artery perfusion. An augmented myocardial turgor (erectile effect) may increase chamber stiffness. ${ }^{31}$ Using a Doppler flow probe, Vatner et al showed that there was a threefold to fivefold increase in left circumflex coronary blood flow in dogs studied during exercise, but coronary flow per beat remained essentially constant. ${ }^{32}$ Despite the reported increase in peak coronary flow during early diastole, ${ }^{32}$ early diastolic filling pressure decreased in our study. Templeton $e t$ al showed that there was no significant alteration in the viscoelastic properties of the left ventricle when coronary flow was altered within moderate limits. ${ }^{33}$ Therefore, the influence of the erectile effect on chamber stiffness during exercise is probably minimal.

Other changes of intrinsic properties include incomplete relaxation, increased viscous resistance, and an altered passive myocardial elasticity. In the present study, however, relaxation was more complete and passive elastic myocardial properties were unlikely to be altered during exercise. The mean passive filling rate increased and viscous resistance probably increased in parallel. ${ }^{3435}$ The calculated index of chamber stiffness $(\Delta \mathrm{P} / \Delta \mathrm{V})$ during exercise was almost double that at rest. Pouleur et al reported that the viscoelastic forces depended on both the lengthening rate and length of the myocardial fibres at the beginning of passive diastolic filling. ${ }^{34}$ In our study the index of chamber stiffness was related not only to mean passive filling rate (lengthening rate) but also to the early filling fraction. Because both these values and the volume (length) at the lowest diastolic pressure increased during exercise, it is likely that viscoelastic forces were increased and that this led to an increase in chamber stiffness. Robinson et al examined the effect of acute expansion of blood volume on the cardiac response to maximal upright exercise in six men with minimal cardiac disease. An increase in stroke volume and cardiac output (measured by dye dilution) after augmentation of blood volume was accompanied by a slight increase $\mathrm{i} \overline{\overline{\bar{n}}}$. right atrial pressure at rest. During exercise, the expansion of blood volume induced no increase i stroke volume, but it did cause a considerable increase in right atrial pressure. These finding suggest an effect on the steepest portion of the pressure-volume relation where end diastolic volume would be little affected by an increase in filling pressure.

LIMITATIONS OF THE STUDY

Many methods have been used to assess diastolif compliance; ${ }^{37}{ }^{38}$ we decided to assess overall diastolie passive filling expressed as the average rate of chand in left ventricular volume over the interval from the lowest diastolic pressure to end diastolic pressure. This simple technique avoids many of the assum tions that are implicit in assuming a monoexponentiat diastolic pressure-volume relation, and avoids the errors of fitting a curve to a few points measures during exercise. ${ }^{2139}$ The validity of the method we used depends upon the accuracy of the componem measurements and the magnitude of $\Delta \mathrm{P}$. A fluid fille catheter system overestimates the lowest fillin pressure whereas the overshoot with a micromanof meter is minimal. ${ }^{40}$ During exercise, however, whe? pressure changes rapidly, the changes in intravero tricular pressure may not accurately reflect changes of intramural pressure because of possible distortio by the fluid coupling between the myocardium and the pressure sensor-that is, the blood in the ventr? cle. We do not know whether and to what extent the dissociation of intramural and intraventricular fluid dynamics influenced our measurements of diastoli chamber stiffness.

The results of the present analysis of diastole properties during supine exercise may not be applicable to exercise in the upright position, becauss in the supine position the pressure-volume relation was already on a steeper portion at rest (because of a increase in preload) than it was in the upright position. During exercise in both positions, howeve the gradient of the pressure-volume relation becanft steeper than under resting conditions. ${ }^{11}$ Even if the are differences at rest, the change in left ventricular chamber stiffness during exercise is similar in bot the supine and upright position.

It is concluded that the decrease in early diastolio filling pressure during exercise in normal subjects caused by the combined effect of faster and more complete relaxation and increased elastic recoil. $A \frac{\mathrm{M}}{2}$ increase in the slope of the passive diastolic pressure 
volume curve is the result of the increased viscoelastic resistance of the left ventricular wall. Enhanced decay of early diastolic pressure permits an increase stroke volume despite augmented diastolic viscous resistance and chamber stiffness during supine submaximal exercise.

\section{References}

1 Rushmer RF, Smith O, Franklin D. Mechanism of cardiac control in exercise. Circ Res 1959;7:602-27.

2 Vatner SF, Franklin D, Higgins CB, Patrick T, Braunwald E. Left ventricular responses to severe exertion in untethered dogs. $J$ Clin Invest 1972;51:3052-60.

3 Tomoike H, Franklin D, McKown D, Kemper WS, Guberek M, Ross J Jr. Regional myocardial dysfunction and hemodynamic abnormalities during strenous exercise in dogs with limited coronary flow. Circ Res 1978;42:487-96.

4 Sharma B, Goodwin JF, Raphael MJ, Steiner RE, Rainbow RG, Taylor SH. Left ventricular angiography on exercise. A new method of assessing left ventricular function in ischaemic heart disease. $\mathrm{Br}$ Heart $J$ 1976;38:59-70.

5 Poliner LR, Dehmer GJ, Lewis SE, Parkey RW, Blomqvist CG, Willerson JT. Left ventricular performance in normal subjects: a comparison of the responses to exercise in the upright and supine position. Circulation 1980;62:528-34.

6 Carroll JD, Hess OM, Studer NP, Hirzel HO, Krayenbuehl HP. Systolic function during exercise in patients with coronary artery disease. J Am Coll Cardiol 1983;2:206-16.

7 Braunwald E, Goldblatt A, Harrison DC, Mason DT. Studies on cardiac dimensions in intact, unanesthetized man: effects of muscular exercise. Circ Res 1963;13:460-7.

8 Braunwald E, Sonnenblick EH, Ross J Jr, Glick G, Epstein SE. An analysis of the cardiac responses to exercise. Circ Res 1967;20/21(suppl 1):44-58.

9 Aroesty JM, McKay RG, Heller GV, Royal HD, Als AV, Grossman W. Simultaneous assessment of left ventricular systolic and diastolic dysfunction during pacing-induced ischemia. Circulation 1985;71:889900.

10 Pièrard LA, Serruys PW, Roelandt J, Meltzer RS. Left ventricular function at similar heart rates during tachycardia induced by exercise and atrial pacing: an echocardiographic study. Br Heart J 1987;57:154-60.

11 Higginbotham MB, Morris KG, Williams RS, McHale PA, Coleman RE, Cobb FR. Regulation of stroke volume during submaximal and maximal upright exercise in normal man. Circ Res 1986;58:281-91.

12 Eichhorn P, Grimm J, Koch R, Hess OM, Carroll JD, Krayenbuehl HP. Left ventricular relaxation in patients with left ventricular hypertrophy secondary to aortic valve disease. Circulation 1982;65:1395-404.

13 Weisfeldt ML, Weiss JL, Frederiksen JW, Yin FCP. Quantification of incomplete left ventricular relaxation: relationship to the time constant for isovolumic pressure fall. Eur Heart J 1980;1(suppl A):119-29.
14 Dodge HT, Sandler H, Baxley WA, Hawley RR. Usefulness and limitations of radiographic methods for determining left ventricular volume. Am J Cardiol 1966;18:10-24.

15 Ishida Y, Meisner JS, Tsujioka K, et al. Left ventricular filling dynamics: influence of left ventricular relaxation and left atrial pressure. Circulation 1986;74: 187-96.

16 Carroll JD, Widmer R, Hess OM, Hirzel HO, Krayenbuehl HP. Left ventricular isovolumic pressure decay and diastolic mechanics after postextrasystolic potentiation and during exercise. $\mathrm{Am} \mathrm{J}$ Cardiol 1983;51:583-90.

17 Carroll JD, Hess OM, Hirzel HO, Krayenbuehl HP. Dynamics of left ventricular filling at rest and during exercise. Circulation 1983;68:59-67.

18 Murakami T, Hess OM, Gage JE, Grimm J, Krayenbuehl HP. Diastolic filling dynamics in patients with aortic stenosis. Circulation 1986; 73:1162-74.

19 Van de Werf F, Boel A, Geboers J, et al. Diastolic properties of the left ventricle in normal adults in patients with third heart sounds. Circulation 1984;69:1070-8.

20 Savitzky A, Golay MJE. Smoothing and differentiation of data by simplified least squares procedures. Anal Chem 1964;36:1627-39.

21 Diamond G, Forrester JS. Effect of coronary artery disease and acute myocardial infarction on left ventricular compliance in man. Circulation 1972;45:11-9.

22 Sonnenblick EH. The structural basis and importance of restoring forces and elastic recoil for the filling of the heart. Eur Heart J 1980;1(suppl A):107-10.

23 Tamiya K, Sugawara M, Sakurai Y. Maximum lengthening velocity during isotonic relaxation at preload in canine papillary muscle. Am J Physiol 1979;237: H83-9.

24 Yellin EL, Hori M, Yoran C, Sonnenblick EH, Gabbay $S$, Frater RWM. Left ventricular relaxation in the filling and nonfilling intact canine heart. Am J Physiol 1986;250:H620-9.

25 Suga H, Goto Y, Igarashi Y, Yamada O, Nozawa T, Yasmura $Y$. Ventricular suction under zero source pressure for filling. Am J Physiol 1986;251:H47-55.

26 Carroll JD, Hess OM, Hirzel HO, Krayenbuehl HP. Exercise-induced ischemia: the influence of altered relaxation on early diastolic pressure. Circulation 1983;67:521-8.

27 Weisfeldt ML, Frederiksen JW, Yin FC, Weiss JL. Evidence of incomplete left ventricular relaxation in the dogs. J Clin Invest 1978;62:1296-302.

28 Pasipoularides A, Mirsky I, Hess OM, Grimm J, Krayenbuehl HP. Myocardial relaxation and passive diastolic properties in man. Circulation 1986;74:9911001.

29 Frederiksen JW, Weiss HL, Weisfeldt ML. Time constant of isovolumic pressure fall: determinants in the working left ventricle. Am J Physiol 1978; 235:H701-6.

30 Raff GL, Glantz S. Volume loading slows left ventricular isovolumic relaxation rate: evidence of loaddependent relaxation in the intact dog heart. Circ Res 
$1981 ; 48: 813-24$.

31 Salisbury PF, Cross CE, Rieben PA. Influence of coronary artery pressure upon myocardial elasticity. Circ Res 1960;8:794-800.

32 Vatner SF, Higgins CB, Franklin D, Braunwald E. Role of tachycardia in mediating the coronary hemodynamic response to severe exercise. J Appl Physiol 1972;32:380-5.

33 Templeton GH, Wildenthal K, Mitchell JH. Influence of coronary blood flow on left ventricular contractility and stiffness. Am J Physiol 1972;223:1216-20.

34 Pouleur H, Karliner JS, LeWinter MM, Covell JW. Diastolic viscous properties of the intact canine left ventricle. Circ Res 1979;45:410-9.

35 Rankin JS, Arentzen CE, McHale PA, Ling D, Anderson RW. Viscoelastic properties of the diastolic left ventricle in the conscious dog. Circ Res 1977; 41:37-45.
36 Robinson BF, Epstein SE, Kahler RL, Braunwald E $\frac{T}{\mathbb{D}}$ Circulatory effects of acute expansion of blood volume: studies during maximal exercise and at rest ${ }_{c}^{-}$ Circ Res 1966;19:26-32.

37 Mirsky I. Assessment of passive elastic stiffness of cardiac muscle: mathematical concepts, physiologif and clinical considerations, directions of future research. Prog Cardiovasc Dis 1976;28:277-308.

38 Glantz SA, Parmley WW. Factors which affect the diastolic pressure-volume curve. Circ Res 1978, 42:171-8.

39 Grossman W, McLaurin LP, Rolett E. Alterations in left ventricular relaxation and diastolic compliance in congestive cardiomyopathy. Cardiovasc Res 1979; 13:514-22.

40 Grossman W. Pressure measurement. In: Grossman W, ed. Cardiac catheterization and angiography. Philadelphia: Lea and Febiger, 1980:103-15. 